\title{
"Who Is Going to Pay for the Wi-Fi?" Exploring Adulthood from the Perspectives of Autistic Youth
}

\author{
Anne V. Kirby, PhD, OTR/L, Marilyn Schneider, MOT, OTR/L, \\ Marissa Diener, $\mathrm{PhD}^{3}$, and Jarrett Henderson, $\mathrm{BS}^{1}$
}

\begin{abstract}
Background: The transition to adulthood involves achievement of objective milestones, yet becoming an adult is also widely considered a subjective experience. Much of the extant research about autistic adulthood focuses on the objective aspects of adulthood, with little emphasis on the subjective experience of adulthood. There is lack of research incorporating the perspectives of autistic youth about preparation for becoming an adult.

Methods: Using semistructured interviews with 27 autistic adolescents (12-17 years old), we examined youth considerations for adulthood. In a subset of the sample $(n=8)$, we also examined youth perspectives on adulthood in general. The research team conducted qualitative thematic analysis with an inductive, iterative approach.

Results: Adolescents considered a variety of factors when considering their plans and desires for adulthood, including their family connections, their own interests and abilities, characteristics of their future situations, and chronological progressions. When speaking about adulthood in general, participants discussed the importance of factors such as age/accomplishment and responsibility/maturity.

Conclusions: This study confirms the appropriateness and importance of conversations with autistic youth about their own adult futures. Understanding how autistic youth understand and consider adulthood can help inform the development of improved supports and services during the transition to adulthood, and promote positive adulthood experiences.
\end{abstract}

Keywords: qualitative, interview, autism, adulthood, transition

\section{Lay Summary}

This article describes a research study that included interviews with 27 autistic adolescents (ages 12-17). During the interviews, the adolescents discussed their plans and desires for their adult lives. Research of this kind is important as it expands understanding of the perspectives of autistic individuals in the discussions about important aspects of their lives. Findings of the study suggested that autistic youth considered a variety of things when thinking about their adult lives including their family connections, their own interests and abilities, characteristics of their future situations, and chronological progressions. When asked about their perspectives on adulthood, participants discussed considerations such as age/accomplishment and responsibility/maturity. These results can help those who are developing services aimed at autistic youth preparing for adulthood. This study also confirms the appropriateness of having discussions with autistic youth about their futures.

\section{Introduction}

A LTHOUGH THERE EXIST objective and legal definitions of adulthood, becoming an adult is considered by many to be a subjectively defined experience. Indeed, the term "emerging adulthood" was coined to refer to the period during which the transition to adulthood has begun but before one considers him or herself to be an adult. ${ }^{.}$Literature with the general population suggests that the subjective ex- perience of becoming an adult commonly involves making decisions about one's own beliefs and values, accepting responsibility for one's actions, and establishing an equal relationship with one's parents. ${ }^{1-3}$ In contrast, objective measures of adult success usually include questions about whether or not youth attained specific milestones such as graduating from college, entering a stable career path, marrying, and becoming a parent. ${ }^{4,5}$ Despite evidence that transitioning to adulthood can be a subjective experience, much of the extant literature

\footnotetext{
${ }_{1}^{1}$ Department of Occupational and Recreational Therapies, University of Utah, Salt Lake City, Utah.

${ }^{2}$ Occupational Therapy Life Skills Clinic, University of Utah, Salt Lake City, Utah.

${ }^{3}$ Department of Family and Consumer Studies, University of Utah, Salt Lake City, Utah.
} 
about autistic ${ }^{*}$ individuals focuses on objective aspects of attaining adulthood. ${ }^{6}$ To expand understanding of the subjective experience of preparing for adulthood and contribute to advancing knowledge to support successful transitions to adulthood, this study used qualitative interviewing with autistic youth to explore their conceptualizations about and considerations for adulthood.

Extant literature suggests autistic individuals typically struggle during the transition to adulthood, especially with the traditional objective measures of adult success. ${ }^{6}$ Specifically, evidence suggests challenges with finding and maintaining employment, and low rates of high school graduation and participation in postsecondary education. ${ }^{8-12}$ Social isolation is also common among autistic adults and the majority of autistic adults are reported to live in supportive settings. ${ }^{13-16}$ Overall, a recent meta-analysis identified that nearly half of autistic adults experience what was considered by researchers to be "poor" objective adult outcomes. ${ }^{17}$ Researchers have also investigated quality of life, suggesting it may be a potentially more valuable adult outcome to study. ${ }^{18}$ Some studies of autistic adults have found quality-of-life scores within a lownormal range; however, the preponderance of evidence suggests lower than typical quality of life for autistic adults. ${ }^{19-21}$ Both objective and subjective aspects of the transition to adulthood are worth examining, and efforts to expand satisfaction with multifaceted aspects of adulthood are needed.

Despite a growing body of literature on the transition to adulthood, there has been little published research incorporating the voices of autistic youth in discussions about their own adulthoods. The studies that do incorporate the perspectives of autistic youth have demonstrated their importance. For example, Cheak-Zamora et al. conducted focus groups with 13 autistic youth, finding that they had worries, fears, and anxieties about various aspects of the transition, and, as a result, were not taking active roles in preparing for their adulthood. ${ }^{22}$ In addition, Anderson et al. interviewed 31 autistic high school students about their postsecondary expectations and definitions of adulthood. ${ }^{23}$ Using a directed content analysis approach, they examined and quantified which domains of adulthood were discussed by the participating youth, including postsecondary education $(90 \%)$, employment $(62 \%)$, friendships $(77 \%)$, and independent or semiindependent living $(42 \%)$. They also examined youth definitions of adulthood, finding that they discussed both traditional and nontraditional adult roles, including individual criteria (e.g., independence), character qualities (e.g., maturity), and, less frequently, transition roles (e.g., finding a job) and chronological age. ${ }^{23}$

In this study, we expand upon existing work by looking beyond what domains of adulthood were discussed to how adolescents are considering their plans for adulthood using inductive qualitative analysis. Specifically, we aimed to understand different factors autistic youth considered when thinking about and preparing for their futures, as well as, more generally, their conceptualizations of adulthood. Our hope is that this exploration can offer insight and guidance to support transitions to adulthood that better meet the needs and desires of youth.

\footnotetext{
"Identity-first language (e.g., "autistic person") is used in this article rather than person-first language (e.g., "person with autism") to align with common preferences of autistic self-advocates ${ }^{7}$ and the editorial preferences of this Journal.
}

\section{Methods}

In this article, we discuss data collected as a part of three separate research studies led by the same principal investigator. To address our stated aims, we first conducted qualitative interviews with eight autistic adolescents (study A). For practical reasons, recruitment stopped at $n=8$. Upon analysis, we felt that saturation was reached for our research question about adolescent conceptualizations of adulthood (i.e., our secondary aim); however, we wanted to collect additional interviews to more fully understand youth considerations for adulthood (i.e., our primary aim). Therefore, we included qualitative interviews in two additional studies (studies B and C). Each study had a primary focus on preparation for adulthood for autistic youth and their families.

All study procedures were approved by university institutional review boards; each caregiver and participant underwent informed consent and assent procedures, respectively. The total group included 8 participants interviewed in North Carolina as part of a qualitative descriptive study (study A), 15 interviewed in Utah at the beginning of a longitudinal mixed-methods project (study B), and 4 interviewed in Utah before the start of a pilot intervention (study C). As a part of each study, we also conducted qualitative interviews with a primary caregiver for each adolescent, which were not included in this analysis.

\section{Participants}

We recruited using emails and printed flyers distributed to local organizations, clinics, and schools that serve autistic youth. Inclusion criteria included youth, ages 14-17 years (studies B and C) or 12-17 years (study A), with a communityobtained diagnosis of autism spectrum disorder or one of its variants (e.g., Asperger's disorder), who were anticipating receipt of a high school diploma (studies B and C), and who caregivers felt could verbally participate in an interview. The 27 included participants had a mean age of $15.6(\mathrm{SD}=1.2)$ years and the overwhelming majority (93\%) were male. Although we did some targeted recruitment for female youth, we had difficulty enrolling more females in the study. Participants identified as white non-Hispanic (78\%), black (15\%), and Hispanic (7\%). Annual household income levels ranged from $<\$ 30,000(11 \%)$ to $>\$ 80,000(56 \%)$. Table 1 contains descriptive information for each participant.

\section{Data collection}

We collected data from semistructured interviews with 27 autistic adolescents. Interview procedures were highly similar across studies; the first author conducted or supervised each interview, ensuring consistency of the interviews across projects. All interviews were conducted face-to-face, verbally in English, either at the participant's home or at a university clinic. The interviewers were experienced working with autistic youth and took care during the interviews to make the youth feel comfortable sharing their thoughts and experiences. The interviews were audio recorded and transcribed verbatim; they lasted between 10 and 27 minutes $(M=16: 55, S D=5: 00)$. Participants received financial incentives (i.e., \$20-25 gift card or check) for participating in interviews.

All participants were asked about their visions for their adult future (i.e., what do you think your life will be like after high school?), but only those in study A were asked about their 
Table 1. Participant Pseudonyms and Descriptions

\begin{tabular}{llclll}
\hline Study & Pseudonym $^{\mathrm{a}}$ & Age & Gender & Racelethnicity & Income \\
\hline A & Alexander $^{\mathrm{b}}$ & 17 & Male & Black & $\$ \$$ \\
A & Amanda $^{\mathrm{a}}$ & 12 & Female & Black & $\$ \$$ \\
A & Anthony $^{\mathrm{a}}$ & 16 & Male & Black & $\$ \$$ \\
A & Armand & 17 & Male & White & $\$$ \\
A & A.J. & 15 & Male & White & $\$ \$$ \\
A & Adam & 17 & Male & White & $\$ \$ \$$ \\
A & Andrew & 14 & Male & White & $\$ \$ \$$ \\
A & Arthur & 17 & Male & Black & $\$$ \\
B & Ben & 15 & Male & White & $\$ \$ \$$ \\
B & Brian & 17 & Male & Hispanic & $\$ \$ \$$ \\
B & Bobby & 16 & Male & White & $\$ \$ \$$ \\
B & Brody & 16 & Male & White & $\$ \$ \$$ \\
B & Beth & 17 & Female & White & $\$ \$$ \\
B & Brad & 15 & Male & White & $\$ \$ \$$ \\
B & Bruce & 15 & Male & White & $\$ \$ \$$ \\
B & Brandon & 15 & Male & White & $\$ \$ \$$ \\
B & Bartholomew & 15 & Male & White & $\$ \$ \$$ \\
B & Blaise & 15 & Male & White & $\$ \$ \$$ \\
B & Brent & 17 & Male & White & $\$ \$ \$$ \\
B & Bert & 16 & Male & White & $\$ \$ \$$ \\
B & Bear & 14 & Male & White & $\$ \$ \$$ \\
B & Bernardo & 15 & Male & Hispanic & $\$ \$$ \\
B & Boris & 15 & Male & White & $\$$ \\
C & Chris & 14 & Male & White & $\$ \$$ \\
C & Charlie & 16 & Male & White & $\$ \$$ \\
C & Connor & 16 & Male & White & $\$ \$$ \\
C & Cody & 16 & Male & White & $\$ \$ \$$ \\
\hline & & & & & \\
\hline
\end{tabular}

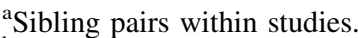

${ }^{\text {b} I n c o m e ~ l e v e l s: ~} \$,<\$ 29,999, \$ \$, \$ 30,000-79,999, \$ \$ \$, \geq \$ 80,000$ annual household income.
}

conceptualizations of adulthood (i.e., what do adults do and how will you know when you are an adult?). When asking youth what they thought their lives would be like after high school, the interviewer prompted with follow-up questions about employment, education, living arrangements, and relationships/ social life if youth did not mention these areas on their own.

\section{Data analysis}

We conducted a thematic analysis of the written interview transcripts using an inductive, team-based approach that involved coding, categorizing, and developing themes. ${ }^{24,25}$ Our iterative process, led by the first author, included reading and rereading the transcripts with frequent group discussions focused on asking questions and making comparisons. ${ }^{26}$ Throughout analysis, we engaged in investigator triangulation to ensure robustness and clarity of the findings. ${ }^{27}$ Upon finalization of the code and theme structure, the first three authors recoded each written transcript in Dedoose (Version 7.6.21). The first author then reviewed and confirmed all final coded data segments, determining saturation was reached for the primary and secondary aims with the included data. The presented results include verbatim quotes to maximize trustworthiness. ${ }^{28}$

\section{Results}

Throughout the results, we use pseudonyms for participants. To indicate which study the participants were from, we have assigned names beginning with $\mathrm{A}, \mathrm{B}$, or $\mathrm{C}$ to participants from studies A to $\mathrm{C}$, respectively.

\section{Youth considerations for adulthood}

During their interviews, youth responded to questions about what they thought their futures might look like and discussed various considerations for their future desires and plans. Identified themes related to their considerations for adulthood included family connections, situational characteristics, personal characteristics, and a step-by-step process (see summary in Table 2). Although we asked about multiple aspects of adulthood (e.g., employment, living arrangements, and social life), the youth tended to focus most of their conversations on employment.

"It runs in our family blood." Many youth in the study related their plans for the future to family or friend connections they had. For some, it seemed that they had developed interests very closely aligned with members of their family and wanted to continue the family tradition. For example, Ben wanted to attend the university that his parents had both attended and also wanted to pursue his father's career path. When asked about when he had made his decision to be a veterinarian, he responded, "Oh, back when I was 5. I knew that it was my calling the entire time. And my dad never really had to push me toward it...It's just like, I just knew it." Similarly, Brian was interested in the career field both of his parents worked in, "I love psychology because both my parents have degrees in psychology." Chris expressed interest in joining the military because of his family history, "I would like to go into the military...because it runs in our family blood...great grandpa, he was a belly gunner; my grandpa, he was I think an aerospace engineer; my uncle, he is a marine." When considering where he wanted to live, Blaise said, "I've always wanted to live in California...my dad's Californian."

Other youth discussed family connections not necessarily as corresponding to their interests, but more as good opportunities or potential avenues. For example, Connor had recently held a summer job working for his stepfather at a fast-food restaurant and considered continuing to work there in the future. Similarly, Cody explained, "My uncle works for the tile industry so he is going to give me a job working for his tile company." Bobby described considering attending the university where his father worked, especially because he could get free tuition.

Finally, some youth discussed their awareness of what their family wanted them to do and how that weighed into their thought process. Specifically, Brad explained his interest in computer programming, but said, "My mom wants me to pick another field that relates to computers so that I don't have to just do computer programming, because she thinks there's too many programmers.' Brad then described a conversation he had with his older sister: "We were talking the other day and she does support me just having free choice...don't let my mom choose for me." Blaise also discussed an influence from his parents when considering whether he would want to complete a religious mission during his transition to adulthood. He explained, "They will be happy if I do...they'll be happy if I don't, but really happy if I do.",

"In the robotics industry you get all the cool toys." Youth often integrated comments about various situational characteristics into discussions about their considerations for adulthood. In particular, many of the youth discussed locale and physical position as considerations for types of employment. For example, youth stated preferences such as 
Table 2. Summary of Qualitative Themes Describing Youth Considerations for Adulthood

\begin{tabular}{|c|c|c|}
\hline Theme title $e^{\mathrm{a}}$ & Theme description & Theme examples \\
\hline It runs in our family blood & $\begin{array}{l}\text { Personal connections: plans and desires } \\
\text { for adulthood are tied to family } \\
\text { or friend connections }\end{array}$ & $\begin{array}{l}\text { Desire to attend same university that parents } \\
\text { did or follow same career path } \\
\text { Plan to work for an uncle, parent, or friend }\end{array}$ \\
\hline $\begin{array}{l}\text { In the robotics industry } \\
\text { you get all the cool toys }\end{array}$ & $\begin{array}{l}\text { Situational characteristics: plans and desires } \\
\text { for adulthood related to the nature } \\
\text { of a job or living situation }\end{array}$ & $\begin{array}{l}\text { Desire to work indoors or outdoors } \\
\text { Desire to work with animals or children } \\
\text { Desire to have a job with high pay } \\
\text { Desire to live in a place that meets } \\
\text { certain criteria }\end{array}$ \\
\hline $\begin{array}{l}\text { I've got a mind that } \\
\text { can problem solve }\end{array}$ & $\begin{array}{l}\text { Personal characteristics: plans and desires } \\
\text { for adulthood related to aspects } \\
\text { of themselves }\end{array}$ & $\begin{array}{l}\text { Desire to work in a job related to their } \\
\text { interests or abilities } \\
\text { Considering what they are good at } \\
\text { Considering limitations of their diagnoses }\end{array}$ \\
\hline $\begin{array}{l}\text { I'm going to have a puppy } \\
\text { child before a real child }\end{array}$ & $\begin{array}{l}\text { Chronological progressions } \\
\text { (step-by-step process): plans } \\
\text { and desires for adulthood } \\
\text { are viewed in a progressive way }\end{array}$ & $\begin{array}{l}\text { Attend college before seeking employment } \\
\text { Rent with friends before buying a home } \\
\text { Live with parents first and move } \\
\text { out when ready } \\
\text { Meet a partner, get married, then move out } \\
\text { Attend a } 2 \text {-year college, then a } 4 \text {-year } \\
\text { Join the military or complete a religious } \\
\text { mission first, then go to college }\end{array}$ \\
\hline
\end{tabular}

${ }^{\mathrm{a}}$ Theme titles are based on participant quotes that were emblematic of the respective theme.

"Working at a desk" (Beth), "I don't want to be cramped inside an office or anything, I have to move around" (Anthony), "A job where I can work from home" (Bruce), and "I'd want to work with my hands" (Bobby). Youth also described what types of things or people they would want to interact with at a job, for example, working with animals, children, or certain equipment. Brody contemplated what types of equipment he would like to work with, stating, "I'm kind of interested in going into the construction industry because you get all the big toys there, but in the robotics industry you get all the cool toys."

Many youth also talked about the pay associated with various jobs, wanting to earn high salaries. For example, Chris talked about how welders can "make pretty big money" as one reason he was considering that career path. Others were looking for jobs that could be enjoyable; Brandon said he wanted "a job that is easy to do and fun." Bruce expressed interest in working in the video game industry because he had heard stories about office culture in which employees "Spend all night and order pizza, and that sounds really cool!" Although A.J. was not sure exactly what type of job he wanted, he summarized his ideal job as one that met situational characteristics as well as personal characteristics (e.g., personal interest), which are expanded upon in the next section: "I want a job that involves indoor and outdoor, that's good paying, that I'm actually interested in...that has an office, I guess."

Beyond the relationship of this theme with employment, participants also discussed situational characteristics of places to live, their forms of transportation, and their adult relationships. Bill described, "I don't really want to do college, because it's hard, and it'd cost a lot of money." A.J. explained why he was interested in living in Oregon, "Well, it has things like mountains, the pacific ocean, my favorite ocean that is." Connor considered factors that would determine where he would live, "If I have enough money I will move out and buy another house. But then who is going to pay for the Wi-Fi?"
"I've got a mind that can problem solve." Youth also incorporated considerations about their own characteristics when discussing their future plans and desires. Specifically, they spoke often about their interests and preferences, and how to tie those into future plans such as related employment. Participants discussed skills or talents they feel they have. For example, Ben said, "I have the talent and I have the skills necessary to do this" and "I'm not bothered by blood and guts." Adam stated, "I'm good at making comic strips, I'm hoping to turn that into a business someday." Other skills and interests participants discussed related to their futures included creating art (e.g., costumes, drawings, and graphic design), writing, sports, computers, video games, problem solving, working with animals, working with children, helping people, and flying planes. Some youth also talked about their own limitations. Cody stated, "I plan on getting an okay job I guess, 'cause I'm not all that smart." He also talked about being limited by a co-occurring psychiatric diagnosis, "I thought about being in and joining the military, but...I can't because I'm bipolar." Similarly, Beth spoke about her current struggle with an eating disorder and how that could affect her adult plans. Brian said, "socially I'm just not very good," explaining that this could impact his ability to have future relationships.

"I'm going to have a puppy child before a real child." Discussion of timelines was common among the participants. Specifically, they often laid out a plan that they would first do something before something else with regard to their plans and desires for adulthood. Regarding his living situation, Blaise discussed, "I would probably be living in an apartment for a little bit until I really started to get in some good money...started to really establish myself, then I might move into a house." Many youth discussed needing money before being able to live on their own. Others had timelines related to finding a partner; Brad explained, "After college, I guess I would try and get an apartment until I found a girl." Ben 
discussed wanting to have or adopt children, but stated, "I'm going to have a puppy child before a real child." Brandon discussed starting off small and building experience with employment, "get a small job and build up from there."

Alexander discussed his plan to transfer between schools; "I'll go for the 2-year track and then I can transfer to a 4-year [college]." Brent wanted to start college, leave, and then return; "I kind of have a plan...okay, I graduate, a few years of college, I go on a [religious] mission, and then I finish college." Youth often had plans for obtaining employment after finishing college. Bert said, "After I get the degree, I want to start my own company." Some participants discussed graduate school; Brian reported that his plan was to get a Bachelor's degree, "and then go get my MBA in business."

\section{Secondary results}

As a secondary aim, we also examined youth conceptualizations of adulthood among the participants of study A $(n=8)$ in response to two general questions: (1) what do adults do and (2) how will you know when you are an adult?

What do adults do? In response to the question, "what do adults do?"' we identified three general themes: productive activities, care for self and others, and handle difficult situations. Productive activities described by participants included having jobs, making money, and paying for things. Armand described that adults do, "A lot of work...email, make presentations, helping run the economy." Youth also described that adults take care of themselves and others through activities such as shopping, cooking, helping people in need, and having children. A.J. explained that adults, "Make good money, like enough to support a family." Participants also explained that adults need to be able to handle difficult situations. Anthony stated that adults are, "responsible, do the right thing, and take action when necessary...if there's a situation it should be handled correctly." Adam explained that being an adult is about, "being mature and being prepared...for maybe problems that people may have."

How will you know when you are an adult? In response to the question "how will you know when you are an adult?" we identified two general themes: age/accomplishment and maturity/responsibility. Regarding age and accomplishment, youth discussed certain milestones associated with them becoming adults including turning 18 years of age, graduating high school, or graduating college. Youth also spoke about maturity and responsibility. Alexander said that you know you are an adult, "when you're required to make all of your decisions on your own." Amanda explained maturity and responsibility this way:

People say 19 is an adult, but some people when they turn 19 , they're still not mature enough ...it's not about age, it's about respect, maturity, how you treat others, and everything because...if you're not responsible, you're not gonna end up anywhere.

\section{Discussion}

The current project focused on examining the perspectives of autistic youth about their own adult futures. Through interviews with 27 youth in two U.S. states, we gained novel insights into youth considerations for adult life, which can inform interventions to support youth and families in preparing for the transition to adulthood. Notably, participants talked almost exclusively about what are often considered the more "objective" measures of adulthood when discussing what they hoped their adulthoods would look like. This included going to college, having a career, making money, getting married, and having children. Employment was the most commonly discussed aspect of adulthood among the participants. Subjective aspects of adulthood discussed in the literature, such as quality of life, were not explicitly described by participants, and discussion of relationships (e.g., friendships and marriage) was minimal. However, it is possible to infer that subjective considerations were implicit in some of their desires for the future. For example, it is likely that the common experience of wanting to apply their interests to a career was discussed because they want to enjoy their work and facilitate happiness in adulthood. It is also possible that youth do not think as much about dimensions such as quality of life and happiness in adulthood because those are not the aspects of adulthood promoted by those around them. It is likely that family members, teachers, and other adults emphasize employment in conversations in attempts to help the youth prepare for adulthood.

In general, we found that the youth in our studies felt positively about their futures and had high aspirations for what they would accomplish as adults. We are unable to evaluate whether or not their expectations for the future are "realistic"; however, we did find that their parents often did not speak as optimistically about their children's futures during separate parent interviews. ${ }^{29}$ This is not unexpected; prior research has suggested autistic youth and their parents may not be aligned in their visions of adulthood. ${ }^{22}$ Furthermore, in a nationally representative study of youth with disabilities, parents of autistic youth were reported to have lower expectations for adult outcomes than most other disability groups, and parents across disability categories were found to have lower expectations for youth than the youth have for themselves. ${ }^{30,31}$ Discrepancies between parent and youth expectations for the future could lead to increased stress for families during the transition to adulthood. Moreover, the literature on expectations suggests that higher expectations are associated with more positive outcomes. $^{32,33}$ Therefore, it may be beneficial to encourage parents to be mindful of the aspirations that autistic youth have about their futures and set ambitious goals to work toward during the transition to adulthood.

Through qualitative data analysis, we identified four themes addressing our primary research question related to youth considerations for adulthood, including (1) connections with their families, (2) their own interests and abilities, (3) characteristics of future situations, and (4) chronological progressions. Recommended transition planning practices include a focus on youth interests and abilities as well as considerations of situational characteristics. However, practitioners should ensure that youth are engaged throughout this process so that their perspectives about their own interests, abilities, and limitations are considered as well as situational characteristics that are appealing to them. Implications for transition planning related to these findings could also include giving attention to familial connections by specifically asking youth what types of work members of their family are engaged in and if they have ever considered similar work. Based on the findings in this study, youth may be motivated to follow in family footsteps or 
may be interested in taking advantage of other family connections, of which practitioners should be aware.

Similar to our finding of chronological progressions, participants in the study by Anderson et al. also referred to adult events in a sequenced manner, which the authors identified as an emerging theme. ${ }^{23}$ Our current study expands upon that finding, suggesting it is consistent across qualitative studies. Together, these results suggest autistic youth often consider adulthood as a progressive sequence of events that can vary by individual preference. Therefore, youth may not want to talk about isolated goals, such as graduating high school or attending college, but may benefit from considering a progression of sequenced events in a timeline (e.g., graduate, then attend college, then find employment) so they can visualize how short-term goals can connect to long-term goals.

Our secondary results, related to understanding youth perceptions of adulthood in general (i.e., what do adults do? and how will you know when you are an adult?), also shared some similarities to the findings of Anderson et al. ${ }^{23}$ Anderson et al. identified that participants defined adulthood using individual criteria (e.g., financial independence and independent living) and character qualities (e.g., responsibility and maturity), and less often with transition roles (e.g., obtaining a job) and chronological age. In our sample, transition roles and chronological age were commonly discussed along with both individual criteria and character qualities. Specifically, we identified productive activities, care of self and others, and handling difficult situations as actions of adults, and age/accomplishment and responsibility/maturity as criteria for adulthood from the perspectives of the participants from study A.

Overall, we found our interviewing approach to be successful. Although youth participants varied in how much information they provided during their interviews, they each completed an interview resulting in analyzable information. We instituted a number of practices that we believe helped ensure success of the interviews. Specifically, we spent the first few minutes of every interview trying to build rapport with the participants, focused on them getting comfortable and willing to talk. Our interviewers had extensive experience working with autistic youth, which supported successful conversations. In addition, the interviewers positioned themselves diagonally across a table to the participants so as not to make the participants feel that they were being interrogated or that they had to make eye contact with the interviewer.

\section{Strengths and Limitations}

This study has a number of strengths and limitations to consider. Broadly, this study has limitations similar to many qualitative studies including the use of a convenience sample and overall inability to generalize the findings to a broad population. Rather, the study provides insight into the perspectives of the included participants, who were American adolescents with community-obtained autism diagnoses, able and willing to participate in semistructured interviews about their futures. Our sample of 27 is relatively high for an in-depth qualitative study; however, our use of only 8 participants for our secondary aim could be considered a limitation, despite our assessment that saturation was reached. We had the benefit of incorporating interviews collected from three different research studies, although it is possible differences in study procedures could have affected the findings. Inclusion of interviews with adolescents from two different U.S. states is a benefit in that it expands the relevance of the findings to a broader group. Unfortunately, we had difficulty enrolling autistic females into our studies. In study A, we expanded our age range to include youth as young as 12 to enroll the one female whose parent contacted the study. For study B, to mitigate expected recruitment difficulty, we specifically requested flyers be sent to any known families who had autistic daughters and attempted female-specific snowball recruiting. Despite these efforts, only 2 out of 27 participants were females, which is low considering an expected 4.5:1 male to female ratio in the population. ${ }^{34}$ There is a high need for research on autistic females, including about the transition to adulthood, and additional efforts are needed to recruit females into all types of autism studies. ${ }^{35,36}$

This study contributes the perspectives of autistic youth into the important ongoing conversation in the research literature about the autistic transition to adulthood. Inclusion of these perspectives is critical to a more complete understanding of factors that should be considered during transition planning. This study also confirms the appropriateness and importance of conversations with autistic youth about their own adult futures.

\section{Acknowledgments}

Funding to support the studies included in this article came from a number of sources including a Society for the Study of Occupation (SSO:USA) Student Research Grant (study A), a University of Utah College of Health Seed Grant (study B), and a Consortium for Families and Health Research Pilot Grant (study C). A portion of Dr. Kirby's and Mr. Henderson's time was also supported through the University of Utah Program in Personalized Health and National Center for Advancing Translational Sciences of the National Institutes of Health under Award Number KL2TR001065. The content is solely the responsibility of the authors and does not necessarily represent the official views of the National Institutes of Health. The authors would like to thank the organizations in North Carolina and Utah that supported recruitment and the additional graduate students who assisted with data collection, transcribing, and preliminary analysis, including Carly Taylor, Rachel Shackelford, and Kelli Garfield. Thank you most especially to the youth who participated in interviews with us.

\section{Authorship Confirmation Statement}

A.V.K. conceived of the study, conducted the majority of interviews, analyzed the data, and drafted the article. M.S. participated in interview transcription and data analysis, and edited the article. M.D. assisted with study planning and editing the article. J.H. participated in interview transcription and data analysis, and edited the article. All authors have reviewed and approved this article. This article is submitted solely to Autism in Adulthood and is not published, in press, or submitted elsewhere.

\section{Author Disclosure Statement}

No competing financial interests exist.

\section{References}

1. Arnett JJ. Are college students adults? Their conceptions of the transition to adulthood. J Adult Dev. 1994;1(4):213-224. 
2. Arnett JJ. Young people's conceptions of the transition to adulthood. Youth Society. 1997;29:3-23.

3. Arnett JJ. Emerging Adulthood: The Winding Road from the Late Teens Through the Twenties (2nd ed.). Oxford, United Kingdom: Oxford University Press; 2014.

4. Hogan DP, Astone NM. The transition to adulthood. Annu Rev Sociol. 1986;12:109-130.

5. Repetti R, Flook L, Sperling J. Family influences on development across the lifespan. In: Fingerman KL, Berg CA, Smith J, Antonucci TC, eds. Handbook of Life-span Development. New York: Springer; 2011.

6. Henninger NA, Taylor JL. Outcomes in adults with autism spectrum disorders: A historical perspective. Autism. 2013; 17:103-116.

7. Brown L. Identity-first language. Accessed March 8, 2018 from: http://autisticadvocacy.org/about-asan/identity-firstlanguage

8. Shattuck PT, Narendorf SC, Cooper B, Sterzing PR, Wagner M, Taylor JL. Postsecondary and employment among youth with an autism spectrum disorder. Pediatrics. 2012;129:1042-1049.

9. Taylor JL, Henninger NA, Mailick MR. Longitudinal patterns of employment and postsecondary education for adults with autism and average-range IQ. Autism. 2015;19:785-793.

10. Cimera RE, Cowan RJ. The costs of services and employment outcomes achieved by adults with autism in the US. Autism. 2009;13:285-302.

11. Hendricks DR, Wehman P. Transition from school to adulthood for youth with autism spectrum disorders: Review and recommendations. Focus Autism Other Dev Disabl. 2009;24(2):77-88.

12. Eaves LC, Ho HH. Young adult outcome of autism spectrum disorders. J Autism Dev Disord. 2008;38:739-749.

13. Billstedt E, Gillberg IC, Gillberg C. Aspects of quality of life in adults diagnosed with autism in childhood: A population-based study. Autism. 2011;15(1):7-20.

14. Orsmond GI, Shattuck PT, Cooper BP, Sterzing PR, Anderson KA. Social participation among young adults with an autism spectrum disorder. J Autism Dev Disord. 2013;43:2710-2719.

15. Farley MA, McMahon WM, Fombonne E, et al. Twenty-year outcome for individuals with autism and average or nearaverage cognitive abilities. Autism Res. 2009;2:109-118.

16. Taylor JL, Seltzer MM. Employment and post-secondary educational activities for young adults with autism spectrum disorders during the transition to adulthood. J Autism Dev Disord. 2011;41:566-574.

17. Steinhausen HC, Mohr Jensen C, Lauritsen MB. A systematic review and meta-analysis of the long-term overall outcome of autism spectrum disorders in adolescence and adulthood. Acta Psychiatr Scand. 2016;133:445-452.

18. Bishop-Fitzpatrick L, Hong J, Smith LE, Makuch RA, Greenberg JS, Mailick MR. Characterizing objective quality of life and normative outcomes in adults with autism spectrum disorder: An exploratory latent class analysis. J Autism Dev Disord. 2016;46:2707-2719.

19. Helles A, Gillberg IC, Gillberg C, Billstedt E. Asperger syndrome in males over two decades: Quality of life in relation to diagnostic stability and psychiatric comorbidity. Autism. 2017;21(4):458-469.

20. Hong J, Bishop-Fitzpatrick L, Smith LE, Greenberg JS, Mailick MR. Factors associated with subjective quality of life of adults with autism spectrum disorder: Self-report versus maternal reports. J Autism Dev Disord. 2016;46:1368-1378.

21. van Heijst BF, Geurts HM. Quality of life in autism across the lifespan: A metaanalysis. Autism. 2015;19:158-167.
22. Cheak-Zamora NC, Teti M, First J. 'Transitions are scary for our kids, and they're scary for us': Family member and youth perspectives on the challenges of transitioning to adulthood with autism. J Appl Res Intellect Disabil. 2015;28:548-560.

23. Anderson KA, McDonald TA, Edsall D, Smith LE, Taylor JL. Postsecondary expectations of high-school students with autism spectrum disorders. Focus Autism Other Dev Disabl. 2015;31(1):16-26.

24. Coffey A, Atkinson P. Making Sense of Qualitative Data: Complementary Research Strategies. Thousand Oaks, CA: Sage Publications, Inc.; 1996.

25. Rubin HJ, Rubin IS. Qualitative Interviewing: The Art of Hearing Data (2nd ed.). Thousand Oaks, CA: Sage Publications, Inc.; 2005.

26. Corbin J, Strauss A. Basics of Qualitative Research (3rd ed.): Techniques and Procedures for Developing Grounded Theory. Thousand Oaks, CA: SAGE Publications, Inc.; 2008.

27. Merriam SB. Qualitative Research: A Guide to Design and Implementation. San Francisco: Jossey Bass; 2009.

28. Creswell JW. Qualitative Inquiry and Research Design (3rd ed.). Thousand Oaks, CA: Sage Publications, Inc.; 2013.

29. Kirby AV, Diener M, Taylor C, Wright C, Wright S. Narratives about the transition to adulthood: Parent and adolescent differences in visions of the future. Proceedings from the International Meeting for Autism Research; May 10-13, 2017; San Francisco, CA. Abstract 25846. Accessed March 8, 2018 from: https://insar.confex.com/insar/2017/webprogram/Paper 25846.html

30. Newman L. Family expectations and involvement for youth with disabilities. A Report from the National Longitudinal Transition Study-2. NLTS2 Data Brief 2005;4(2):1-5.

31. Wagner M, Newman L, Cameto R, Levine P, Marder C. Perceptions and Expectations of Youth With Disabilities. A Special Topic Report of Findings From the National Longitudinal Transition Study-2 (NLTS2) (NCSER 2007-3006). Menlo Park, CA: SRI International; 2007. Accessed March 8, 2018 from: https://nlts2.sri.com/reports/2007_08/ nlts2_report_2007_08_complete.pdf

32. Eccles JS, Wigfield A. Motivational beliefs, values, and goals. Аnпu Rev Psychol. 2002;53:109-132.

33. Kirby AV. Parent expectations mediate outcomes for young adults with autism spectrum disorder. J Autism Dev Disord. 2016;46:1643-1655.

34. Centers for Disease Control and Prevention. Prevalence of autism spectrum disorder among children aged 8 yearsAutism and developmental disabilities monitoring network, 11 sites, United States, 2010. MMWR Morb Mortal Wkly Rep. 2014;63:1-21.

35. Interagency Autism Coordinating Committee. IACC strategic plan for autism spectrum disorder research: 2013 update. 2013. Accessed March 8, 2018 from: https://iacc.hhs.gov/ publications/strategic-plan/2013/

36. Taylor JL, Mailick MR. A longitudinal examination of 10-year change in vocational and educational activities for adults with autism spectrum disorders. Dev Psychol. 2014;50(3):699-708.

Address correspondence to: Anne V. Kirby, PhD, OTR/L

Department of Occupational and Recreational Therapies University of Utah 520 Wakara Way Salt Lake City, UT 84108

E-mail: avkirby@gmail.com 